\title{
Increasing Student Talk Time Through Vlogging
}

\author{
Jon Watkins \\ Kwansei Gakuin University, Hyogo, Japan
}

\begin{abstract}
While audio diaries for second language $(\mathrm{SL})$ / foreign language $(\mathrm{FL})$ oral communication students have been in use for decades, recent advances in computer technology have enabled students to replace audiocassette tapes with audio stored on the Internet. Additionally, the rise of Internet video hosting sites presents both learners and teachers with free virtual space where spoken recordings can be hosted. This paper details how vlogs - a portmanteau of the words video and blog - can be used in an oral communication classroom. By vlogging, students can practice English speaking skills outside the classroom, give oral feedback on other students' vlogs, and receive teacher feedback through the teacher's vlog posting. In addition to describing the software and hardware needed for both teachers and students, this paper proposes a loose framework along which such a course could be structured.
\end{abstract}

Foreign language $(\mathrm{FL})$ learning contexts often suffer a drawback in the communicative approach to language teaching. While FL students can converse and be communicative with each other inside the classroom, finding ways to practice oral communication outside the classroom is often a significant challenge. Occasionally, a student will be lucky to have a local friend who speaks the L2 or an employment situation in which L2 communication is possible, but for the most part, class homework is done silently (for reading and writing) or passively (in the case of listening assignments). As a result, crucial aspects of language learning, such as consistently accurate pronunciation and oral fluency, are largely rewards for students fortunate enough to study abroad.

\section{Literature Review}

There are a few methods that FL teachers often employ to have their students speak the L2 more outside the classroom. Assigning practice for an upcoming speech is one way; however, this practice is one-sided and non-conversational, and students generally get feedback only after their speech is completed. Another method is to have students form extra-curricular practice groups or circles. While this activity can be beneficial (particularly if participants come from diverse linguistic backgrounds and rely on the L2 for effective communication), such meetings often warp to become more social than academic, causing the L1 to become inadvertently readopted to ease conversational difficulties. An additional method is to employ audiocassette diaries, both for FL (Sutude nama \& Ramazanzadeh, 2011) as well as distance-learning contexts (Dahlman \& Rilling, 2001).

Language Education in Asia, 2012, 3(2), 196-203. http://dx.doi.org/10.5746/LEiA/12/V3/I2/A08/Watkins 
As Internet technology continues to advance, however, additional avenues for FL students to orally practice an L2 are opening up. With the rise of YouTube as a multifaceted video hosting resource, a number of possible language-learning applications are developing (Watkins \& Wilkins, 2011). One such application is vlogging. A vlog is a portmanteau of the words video and $b \log (b \log$ is itself a portmanteau of web and $l o g$ ). Blogs have become an Internet institution for anyone wanting to express an opinion, disseminate information, or simply keep a public diary of his or her personal life. SL / FL student blogs have become a popular method for writing teachers to digitally share, store, and display student composition efforts $(\mathrm{Wu}, 2008)$ or an avenue through which teachers can encourage student collaboration in a digital format (Godwin-Jones, 2003). While blogs are a useful tool for a writing class, vlogs-the video equivalent to blogs-are similarly useful for an oral communication class. The purpose of this paper is to demonstrate how guided vlogging in an FL context can help increase out-of-class student speaking, encourage student-student oral interaction, and provide a useful medium for instructor feedback.

\section{A Rationale for Vlogging in an Oral Communication Class}

There are several reasons why vlogging might be appropriate for an FL oral communication class. A significant reason to consider vlogging is that it increases student talk time. More oral communication practice helps students improve mastery of new vocabulary and grammar, decrease shyness while bolstering confidence, and develop fluency. If students' speaking opportunities are limited to within the walls of the classroom, fluency, confidence, and oral proficiency are similarly limited. However, if a student has reason to continue speaking English after the class is done, away from the confines of the classroom, then the student gains additional practice as well as a personal demonstration that English oral communication practice can be undertaken independently with good benefit.

Another benefit of vlogging is that it encourages self-monitored speaking. Before students submit their vlog to the teacher, they should listen to it themselves. Perhaps they will notice a repeated pronunciation or grammar error or a section of the vlog in which they could have been clearer. Perhaps a crucial detail of a story they were telling was omitted or, if they were arguing a point, perhaps they will notice an area where their argument could be bolstered. Regardless of the reason, if a student decides the original vlog effort was not the best he or she could have done, the student could try again. Similarly, if the instructor feels the student could do better, a second try could be suggested.

A third benefit to vlogging pertains to how teachers (and even fellow students) could submit feedback. While written feedback is always an option, for smaller classes, vlogged feedback could be considered. If a student's vlog is critiqued and the grade delivered in similar form, then that particular student receives listening practice in addition to speaking practice. Additionally, unlike a face-to-face conference with a student, counseling in vlog form offers students the possibility of multiple viewings. Sometimes in a face-to-face conference, the teacher has several pieces of advice for a student; however, the student might be so taken with one of the suggestions that the others become forgotten before the conference is even over. If the student has a vlog of the instructor's advice, then that vlog could be viewed repeatedly before the student next undertakes the next vlog attempt. Additionally, if class rapport is strong enough, students can listen to each other's vlogs and give compliments and criticism where necessary.

\section{Potential Limitations for Vlogging}

The use of video and the Internet might, for some, be a daunting prospect. The notion of possibly setting up a tripod, pointing a video camera at oneself, talking into the camera, saving 
the video, and then converting it to a format readable on most computers before finally finding an Internet location to host the footage might be too overwhelming for some students (and teachers). Additionally, teachers in certain countries, areas, or universities might lack the technology necessary to implement widespread vlogging.

Even if the technology and the capability to use it are present, other practical considerations ought to be taken into account. Class size, for example, is a significant factor when deciding whether or not vlog feedback should be rendered in similar vlog form. Vlogged feedback is time consuming and not recommended to teachers with classes larger than 10 to 15 students. Other factors to consider include student attitude and aptitude. How badly do the students want to improve their oral English? Are they ready to speak independently and extemporaneously alone? Unmotivated students or students on the wrong side of the L2 conversational threshold might create vlogs that are uninspired or merely read aloud from a manuscript, efforts as painful for teachers to listen to and evaluate as they were for students to produce.

\section{Method Suggestions}

If the technology is accessible, the class size is optimal, and the students are ready and willing to engage in the activity, then vlogging can be successfully employed as a cornerstone of an oral communication course. This section will review hardware, software, and hosting web sites, suggest thematic content of vlogs, and examine ways vlogs can be evaluated.

\section{Hardware}

One might assume that students need some type of computer to vlog. While vlogging can certainly be done with a computer, the smartphones of today-equipped with a video camera and Internet capability-allow students to create and post vlogs without ever touching an actual keyboard. If students do want to use a computer, it must have a webcam. A decent webcam, if not already built into the desktop computer or laptop, can be purchased online for less than the price of a common textbook. It should be noted that, as a general rule for any technological application, the newer the hardware, the better the results.

\section{Software}

Without wading into a debate over the superiority of PCs or Macs, a versatile teacher should have the ability to view video files from either format. VLC is an open-source media player that can be downloaded freely to either platform, and it plays video files from both formats (VideoLAN, 2012).

With regard to capturing video from various forms of cameras, sometimes additional software is necessary. PC users can download a freeware version of $\mathrm{NCH}$ Debut video capture software that can transfer videos from a webcam or camera device to a hard drive (NCH Software, n.d.). Mac users can use the Photo Booth application that comes with Mac OS X and iOS 5.1 for iPhone and iPad videos.

Although video editing is not necessary for vlogging, students may enjoy adding music, film clips, images, and written messages into their vlogs. To edit videos, Windows Movie Maker, which comes with Microsoft Windows, can be used with PCs. Mac, iPhone, and iPad users can use iMovie to edit videos. Again, such flourishes are not necessary for a vlog audio diary, but if video editing bolsters student enthusiasm, it should not be discouraged. 


\section{Video Hosting Websites}

Once students have completed their videos, they need to find a way to share them with the teacher and / or the class. Although this can be most easily accomplished through the Internet, if access is problematic, students could submit their vlogs via USB memory cards. If Internet access is available, a number of websites could be considered to host the videos.

YouTube.com is perhaps the most famous online video hosting site, and students are likely to be quite familiar with it already. Setting up an account and uploading a video to YouTube are relatively easy activities. The problem with YouTube lies with privacy. Often students, parents, and / or teachers are concerned with the notion of images being freely viewable by anyone. However, YouTube users can use certain settings to designate their vlogs as private, viewable only to those who receive the exact URL (Uniform Resource Locator).

Facebook is another video hosting option. Teachers can create a private Facebook group for each class, so that the contents are viewable only by class members. Some teachers might be nervous about being Facebook friends with students (and vice versa); however, separate Facebook accounts could be created for the designated purpose of academic interaction. A significant advantage to using YouTube and Facebook for vlogging is that various video types are not an issue-all videos will play on any computer with an Internet connection.

Another option is an Internet-based service called MailVU.com. This site lets users send videos to each other as e-mail, making it an ideal private vlogging service. Conceivable drawbacks are that the service limits each video to 10 minutes in length, and pre-recorded videos cannot be used unless a plan is purchased. Without paying, video editing cannot be done, and only webcams can be used. The benefits are the price (free for most functions), video playback universality (e.g., YouTube and Facebook) and for those very concerned with privacy, a selfdestruct feature, which limits the number of days and times a video can be watched before it deletes itself.

A final vlog hosting option is another free Internet website, the cloud-based storage service, Dropbox.com. Dropbox lets users share 2 gigabytes (at a minimum) of web space with each other. Any kind of file-word processing or PDF documents, audio files, ZIP archives, videos, etc.-can be privately shared online. Students can record and optionally edit their videos and then save the videos to a private Dropbox folder to be viewed only by the teacher or authorized class members.

\section{Lessons and Content}

As homework, vlogs can function in several ways. One idea is for the vlog to be simply a periodic oral diary. Students are encouraged to speak freely and extemporaneously about whatever is on their minds for a specific number of minutes. A second idea is for the teacher to give a certain topic or question for the students to talk through for a specific number of minutes. Some examples might be:

- a general self-introduction

- a how-to demonstration of something the student is good at or a meal he or she is skilled at preparing

- an interview (and simultaneous translation) of an L1 friend or family member

- an introduction of a pet

- a trip to a favorite neighborhood place (if the student is using a smart phone or laptop)

- anything related to content being discussed in class, or a reaction to assigned reading 


\section{Evaluation}

With regard to evaluating student vlogging, any number of standards might be employed. Ideally, these standards ought to reinforce the speaking criteria maintained in class. A possible evaluative framework is detailed in Table 1.

Table 1

Possible Evaluative Framework for Vlogging Assignments

\begin{tabular}{|c|c|}
\hline $\begin{array}{l}\text { Proficiency } \\
\text { Area }\end{array}$ & Evaluative Criteria \\
\hline Vocabulary & $\begin{array}{l}\text { - Is the student using correct and appropriate word choices? } \\
\text { - Should the student employ vocabulary more suitable for an academic } \\
\text { audience? }\end{array}$ \\
\hline Grammar & $\begin{array}{l}\text { - Is the student making progress with grammar usage? } \\
\text { - Do the same grammar mistakes keep happening? } \\
\text { - Do grammar mistakes lead to problems discerning meaning? }\end{array}$ \\
\hline Pronunciation & $\begin{array}{l}\text { - Is the student making consistent and predictable pronunciation errors? } \\
\text { - Do these pronunciation errors make it difficult to understand what the } \\
\text { student is talking about? }\end{array}$ \\
\hline Fluency & $\begin{array}{l}\text { - Is the student talking smoothly and confidently, or is the speech interrupted } \\
\text { by long, awkward pauses? } \\
\text { - Was the speech extemporaneous or obviously read from a manuscript? }\end{array}$ \\
\hline Content & $\begin{array}{l}\text { - Did the student talk for the requested amount of time? } \\
\text { - If the vlog assignment requested reflection on a certain theme or action in } \\
\text { accordance with a set of directions, did the student make efforts to address } \\
\text { this theme and / or follow directions? }\end{array}$ \\
\hline
\end{tabular}

In addition to these criteria, students could evaluate each other in accordance to a different set of criteria, perhaps in accordance to recommendations of the course textbook or to criteria which more fully reflect the principles of the institution's program. Finally, although reading aloud from a pre-written script somewhat negates efforts made at developing students' ability to speak extemporaneously, if oral reading suits the goals of a course, vlogging assignments could be modified to allow it.

\section{Report of Vlogging: Usage in Two Japanese Universities}

The information detailed in this paper has been gleaned from the implementation of vlogging at two Japanese universities during different semesters. Table 2 compares the contexts in the two universities as well as the students engaged in vlogging. 


\section{Table 2}

\section{Comparison of University Vlogging Contexts}

\begin{tabular}{|l|l|l|l|l|}
\hline Semester & Course Title(s) & $\begin{array}{l}\text { Number of } \\
\text { Students }\end{array}$ & $\begin{array}{l}\text { Student Level } \\
\text { and Proficiency }\end{array}$ & $\begin{array}{l}\text { Vlog Activities / Topics } \\
\text { Undertaken }\end{array}$ \\
\hline $\begin{array}{l}\text { Institution 1 } \\
\text { Spring 2011 }\end{array}$ & $\begin{array}{l}\text { International } \\
\text { Business English }\end{array}$ & $\begin{array}{l}5 \text { (in one } \\
\text { section) }\end{array}$ & $\begin{array}{l}\text { Intermediate to } \\
\text { Advanced }\end{array}$ & $\begin{array}{l}\text { 1) Self-introduction } \\
\text { 2) Favorite TV show } \\
\text { 3) How-to meal } \\
\text { preparation } \\
\text { 4) }\end{array}$ \\
$\begin{array}{l}\text { Trip to favorite } \\
\text { neighborhood place } \\
\text { Vlogged classmate } \\
\text { feedback }\end{array}$ \\
\hline $\begin{array}{l}\text { Institution 2 } 2011, \\
\text { Spring 2012 }\end{array}$ & $\begin{array}{l}\text { Pre-Advanced } \\
\text { Communication }\end{array}$ & $\begin{array}{l}24 \text { (in two } \\
\text { sections) }\end{array}$ & $\begin{array}{l}\text { Intermediate to } \\
\text { Advanced }\end{array}$ & $\begin{array}{l}\text { 1) Self-introduction } \\
\text { 2) Regular vlog journal } \\
\text { entries }\end{array}$ \\
\hline
\end{tabular}

There were a number of similarities in implementation between both universities. Although students were not asked to complete a survey detailing their reactions to the vlogging assignment, class discussions in all courses revealed enthusiasm for the endeavor. By vlogging at home, students at both institutions were able to increase out-of-class speaking time. Additionally, all three classes engaged in vlogging regularly for about eight to ten weeks. Finally, for both institutions, instructor vlog examples (both "good vlog" and "bad vlog") were shown to students in class during the initial introduction and also made available in class Dropbox folders to give students an idea as to what was expected.

There were also differences in implementation between the two institutions. A few students in both courses at Institution 2 privately requested that the contents of their vlog remain private from their classmates, so vlogged classmate feedback was not undertaken. The students at Institution 1, however, would do a vlog project one week, and then post vlogged feedback to classmates during the second week. Another difference in implementation was that the students at Institution 1 recorded their vlogs as a series of mini-projects, with each vlog having a distinct theme and instructions to follow. For Institution 2 students, however, vlogging was more of a weekly journaling activity, with an emphasis on free-flowing thoughts and spontaneous speaking.

\section{Conclusion}

Vlogging in the oral communication classroom, as it has been described in this paper, is the product of repeated trials and repeated mistakes. The concepts discussed reflect implementation in oral communication classrooms over three semesters at two Japanese universities. The concepts discussed in this paper additionally reflect a multitude of different technologies; problems using those technologies were often very challenging for students and the instructor. However, a thorough demonstration of how to create a vlog entry and the use of instructor models and sample vlogs, along with a patient outlook, can help make the cultivation of a vlogging component much smoother.

From the experience of the author, frustrations and errors dissipate by the second or third week. As students become used to the activity, vlog quality—and speech quality—steadily improve. 
A more definitive study which solicits student input on vlogging methodology as well as effectiveness or a study in which vlogs are transcribed and student error occurrence and speech fluency are measured longitudinally would be enlightening and worthy of undertaking.

\section{Author Note}

Jon Watkins, Language Center, Kwansei Gakuin University, Hyogo, Japan.

Correspondence concerning this article should be addressed to Jon Watkins, Language Center, Kwansei Gakuin University, 1-155 Uegahara Ichiban-cho, Nishinomiya, Hyogo, Japan 6628501. E-mail: admiral.jon@gmail.com 


\section{References}

Dahlman, A., \& Rilling, S. (2001). Integrating technologies and tasks in an EFL distance learning course in Finland. TESOL Journal, 10(1), 4-8.

Godwin-Jones, R. (2003). Emerging technologies: Blogs and wikis: Environments for on-line collaboration. Language Learning \& Technology, 72), 12-16. Available at http://lt.msu.edu/vol7num2/pdf/emerging.pdf

$\mathrm{NCH}$ Software. (n.d.). Debut video capture software [Computer software]. Canberra, Australia. http://www.nchsoftware.com/capture/index.html

Sutude nama, E., \& Ramazanzadeh, A. (2011). The effect of oral dialogue journals on Iranian EFL learners' communicative competence. Journal of English Language Teaching and Learning, 53, 161-182. Available at http://literature.tabrizu.ac.ir/Files/Sutude\%20nema222.pdf

VideoLAN. (2012). VLC media player (Version 2.0.1) [Computer software]. Paris, France. http://www.videolan.org/

Watkins, J., \& Wilkins, M. (2011). Using YouTube in the EFL classroom. Language Education in Asia, 2(1), 113-119. http://dx.doi.org/10.5746/LEiA/11/V2//1/A09/Watkins_Wilkins

Wu, W.-s. (2008). Using blogs in an EFL writing class. In S. Priya (Ed.), Netlingo: The Metamorphosis of Language (pp. 86-99). Hyderabad, India: The Icfai University Press. 